\title{
$\infty$
}

\section{Structural, Optical and Photoconductive Properties of Chemically Deposited Nanocrystalline CdS Thin Films}

\author{
Wug-Dong Park ${ }^{+}$ \\ Department of Railroad Drive and Control, Dongyang University, Yeongju 750-711, Korea
}

Received June 14, 2011; Revised June 30, 2011; Accepted July 4, 2011

\begin{abstract}
Nanocrystalline cadmium sulphide (CdS) thin films were prepared using chemical bath deposition (CBD), and the structural, optical and photoconductive properties were investigated. The crystal structure of CdS thin film was studied by X-ray diffraction. The crystallite size, dislocation density and lattice constant of CBD CdS thin films were investigated. The dislocation density of CdS thin films initially decreases with increasing film thickness, and it is nearly constant over the thickness of 2,500 $\AA$. The dislocation density decreases with increasing the crystallite size. The Urbach energies of CdS thin films are obtained by fitting the optical absorption coefficient. The optical band gap of CdS thin films increases and finally saturates with increasing the lattice constant. The Urbach energy and optical band gap of the 2,900 $\AA$-thick CdS thin film prepared for 60 minutes are $0.24 \mathrm{eV}$ and $2.83 \mathrm{eV}$, respectively. The activation energies of the 2,900 $\AA$-thick CdS thin film at low and high temperature regions were $14 \mathrm{meV}$ and $31 \mathrm{meV}$, respectively. It is considered that these activation energies correspond to donor levels associated with shallow traps or surface states of CdS thin film. Also, the value of $\gamma$ was obtained from the light transfer characteristic of CdS thin film. The value of $\gamma$ for the $2,900 \AA$-thick CdS thin film was 1 at $10 \mathrm{~V}$, and it saturates with increasing the applied voltage.
\end{abstract}

Keywords: Cadmium sulphide thin films, Chemical bath deposition, X-ray diffraction, Dislocation density, Crystallite size, Urbach energy, Optical band gap, Activation energy

\section{INTRODUCTION}

Nanocrystalline cadmium sulphide (CdS) is one of the attractive semiconductor materials and has been investigated for electronic and optoelectronic devices. Recently, Ghosh et al. [1] reported the field-emission properties of nanocrystalline CdS thin films grown by the chemical bath deposition (CBD) process within the pores of polyvinyl alcohol on $\mathrm{Si}$ and glass substrates. The solar cells of CdS/CdTe $[2,3]$ and $\mathrm{Cu}(\mathrm{In}, \mathrm{Ga}) \mathrm{Se}_{2}$ (CIGS) $[4,5]$ have been researched to increase the efficiency of cells. CdS thin films are prepared by vacuum evaporation [5-7], sputtering [2,8], screen printing [7,9], chemical pyrolysis [10], and CBD $[1,3-5,7]$.

${ }^{\dagger}$ Author to whom all correspondence should be addressed:

E-mail:wdpark@dyu.ac.kr

Copyright $\odot 2011$ KIEEME. All rights reserved.

This is an open-access article distributed under the terms of the Creative Commons Attribution Non-Commercial
License (httr:///creativecommons.org/licenses $/$ by-nc/3.0) which permits unrestricted noncommercial use, License (http:///creativecommons.org/icenses/by-nc/3.0) which permits unrestricted
distribution, and reproduction in any medium, provided the original work is properly cited.
Among the various techniques, CBD is a simple and inexpensive solution deposition technique, in which thin film is prepared by chemical reaction in the solution bath. Also, it is possible to obtain uniform films with good adherence [11]. CBD CdS thin films are prepared by the decomposition of thiourea $\left(\mathrm{SC}\left(\mathrm{NH}_{2}\right)_{2}\right)$ in an alkaline solution containing a cadmium salt, such as cadmium chloride $\left(\mathrm{CdCl}_{2}\right)$, cadmium sulphate $\left(\mathrm{CdSO}_{4}\right)$ and cadmium acetate $\left(\mathrm{Cd}\left(\mathrm{CH}_{3} \mathrm{COO}\right)_{2}\right)$. In the $\mathrm{CBD}$ technique for CdS thin films, the cadmium sulphate, thiourea and ammonium hydroxide serve as the cadmium source, sulphur source and complexing agent, respectively. CBD CdS thin films are prepared by the reaction of $\mathrm{Cd}^{2+}$ complex with $\mathrm{S}^{2-}$. Sulphur ions are supplied by the decomposition of thiourea in an alkaline solution, and cadmium ions are usually complexed by $\mathrm{NH}_{4} \mathrm{OH}$ [12].

The structural and optical properties of CBD CdS thin films depend on the parameters of relative concentration of the reactants for chemical reaction, $\mathrm{pH}$ value of the aqueous solution and bath temperature. The CdS thin films are deposited by the heterogeneous reaction on the glass substrate at low tempera- 


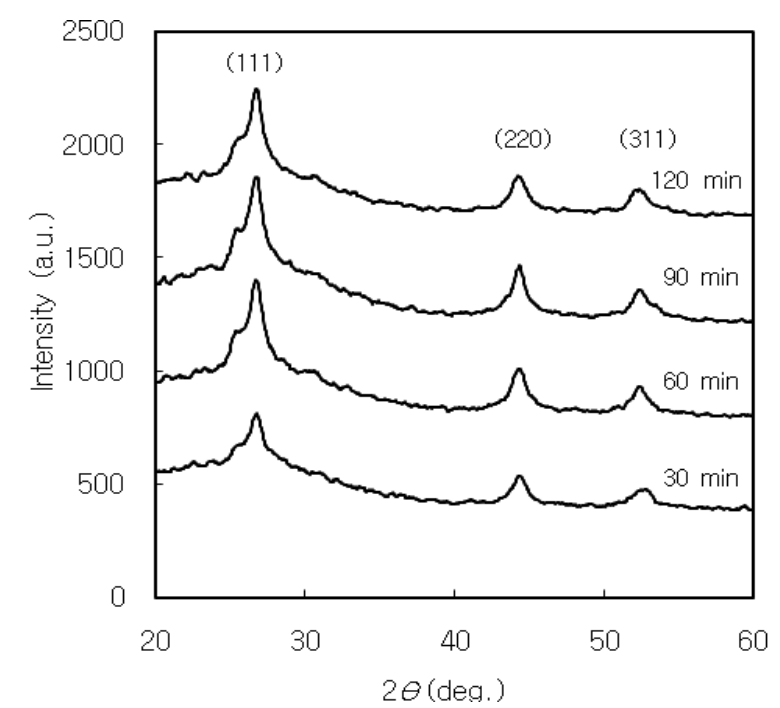

Fig. 1. X-ray diffraction patterns of CdS thin films.

ture. In the CBD process, film growth occurs either (i) by an ionby-ion condensation or (ii) by adsorption of the colloidal particles of CdS on the substrate [13]. The chemically deposited CdS film was found to consist of a continuous film relating to the ion-by-ion deposition of CdS [14]. The structural informations of CdS thin films such as crystal structure, interplanar distance and lattice constant are determined by the X-ray diffraction (XRD). The optical parameters of optical absorption coefficient and optical band gap are important to design the optoelectronic devices.

In this study, nanocrystalline CdS thin films were deposited on glass substrates by CBD. The structural, optical and photoconductive properties of CdS thin films were investigated. The crystal structure was studied using the XRD. Also, the Urbach energy, optical band gap, activation energy and photoconductive characteristic of CdS thin film were investigated.

\section{EXPERIMENTS}

CBD CdS thin films were deposited in an alkaline solution bath containing a cadmium salt, chalcogenide source and complexing agent. The alkaline solution of $0.5 \mathrm{M} \mathrm{CdSO}_{4}, 1 \mathrm{M}$ $\mathrm{SC}\left(\mathrm{NH}_{2}\right)_{2}$ and $25-28 \% \mathrm{NH}_{4} \mathrm{OH}$ was used to prepare nanocrystalline CdS thin films by CBD. The CdS thin films were deposited on cleaned glass substrates. The alkaline solution bath was maintained at $80^{\circ} \mathrm{C}$, and the $\mathrm{pH}$ value of the aqueous solution was 10 . The glass substrates were washed in distilled water and ultrasonically cleaned subsequently in acetone, trichloroethylene and methanol. Then, the substrates were rinsed in deionized water and dried in an oven after $\mathrm{N}_{2}$ blowing. The preparation of CBD CdS thin films is based on the slow release of $\mathrm{Cd}^{2+}$ and $\mathrm{S}^{2-}$ ions in the solution bath. The $\mathrm{Cd}^{2+}$ ions are given by the dissociation of a complex species of cadmium $\left[\mathrm{Cd}\left(\mathrm{NH}_{3}\right)_{4}\right]^{2+}$. The $\mathrm{S}^{2-}$ ions are obtained by the decomposition of thiourea $\left(\mathrm{SC}\left(\mathrm{NH}_{2}\right)_{2}\right)$ in an alkaline solution, and react with $\left[\mathrm{Cd}\left(\mathrm{NH}_{3}\right)_{4}\right]^{2+}$ ions to form CdS thin film $[15,16]$. The CdS thin films were prepared by taking out the glass substrates in a bath at different deposition times from 30 to 120 minutes. The deposited CdS thin films were rinsed in deionized water and cleaned ultrasonically. Then, the CdS thin films were dried in air.

The thickness of CdS thin films was measured by an ellipsometer (L116SF; Gaertner Scientific Co., Skokie, IL, USA). The surface morphology and cross-section of CdS thin films were

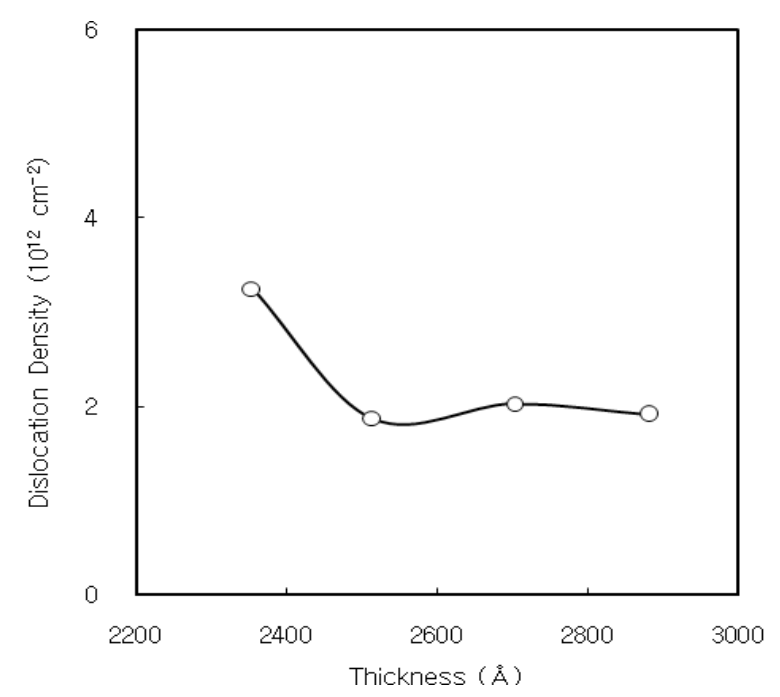

Fig. 2. Dislocation density of CdS thin films as a function of the film thickness.

studied using a field emission scanning electron microscopy (FESEM) (JSM-6700F; Jeol Ltd., Tokyo, Japan). The crystal structure of CdS thin films was studied by XRD using an X-ray diffractometer (X'pert-APD; Philips, The Netherlands) with $\mathrm{Cu} \mathrm{K} \alpha$ radiation $(\lambda=1.5406 \AA)$ at $40 \mathrm{kV}$ and $30 \mathrm{~mA}$. The optical transmission of CdS thin films was measured using a UV-VIS-NIR double beam spectrophotometer (CARY 5G; Varian Inc., Palo Alto, CA, USA) in the wavelength range $350-2,000 \mathrm{~nm}$. The electrical conductivity and photocurrent of CdS thin films were investigated using the DC two probe method. Coplanar In/Ag electrodes for electrical and photoconductive measurements were deposited on CdS thin films by vacuum evaporation. To obtain ohmic contact, the electrodes were annealed at $150^{\circ} \mathrm{C}$ in $\mathrm{N}_{2}$ atmosphere for 5 minutes. The dark current and photocurrent of CdS thin film were measured by an electrometer/high resistance system (6517; Keithley Instruments Inc., Cleveland, OH, USA). The light source was a halogen lamp, while the light intensity was measured by a digital luxmeter.

\section{RESULTS AND DISCUSSION}

In the CBD CdS thin films, the morphology, structural and optical properties depend on the deposition parameters. The CdS thin films prepared by CBD have hexagonal or cubic polycrystalline structure. Cubic CdS grows in the zincblende structure, considered a metastable phase; hexagonal CdS grows in the wurtzite structure, which is the stable phase of the semiconductor [17]. The as-deposited nanocrystalline CdS thin films had a cubic structure. The XRD patterns of CdS thin films are shown in Fig. 1. Three diffraction peaks correspond to (111), (220), and (311) reflections of the cubic phase at $2 \Theta$ of $26.5^{\circ}, 44^{\circ}$ and $52^{\circ}$, respectively. The crystallite size of CdS thin films is determined by the Scherrer formula [18]. The crystallite size of CdS thin film prepared for 60 minutes was $7.2 \mathrm{~nm}$. The crystallite size calculated using the full width at half maximum of the peak from the XRD is smaller than those calculated using absorption spectra. This is considered by the fact that the CdS particles are the aggregation of CdS nanoparticles [19] .

If the crystallite size is known, then the dislocation density of CdS thin films is obtained using the crystallite size [20]. Figure 2 shows the dislocation density of CdS thin films as a function of film thickness. It initially decreases with increasing the film 


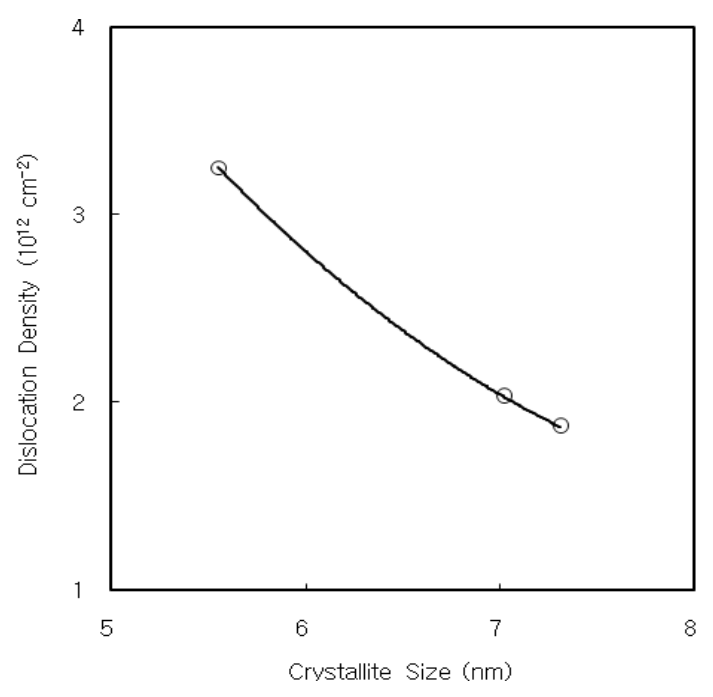

Fig. 3. Dislocation density of CdS thin films as a function of the crystallite size.

thickness, and it is nearly constant over the thickness of 2,500 A. It is considered by the decrease of internal strain with increasing the film thickness. Figure 3 shows the dislocation density of CdS thin films as a function of the crystallite size. The dislocation density decreases with increasing the crystallite size. Also, the interplanar distance and lattice constant of CdS thin films are obtained from the XRD data. The interplanar distance and lattice constant of CdS thin film prepared for 60 minutes was $3.35 \AA$ and $5.81 \AA$, respectively.

To obtain the optical absorption coefficient, the transmittance of CdS thin films was investigated. The optical absorption coefficient $\alpha(E)$ is obtained using the transmittance data as a function of the photon energy [21].

$$
\alpha(E)=-\frac{\ln T}{d}
$$

where $d$ and $T$ are film thickness and transmittance, respectively. The optical absorption coefficient is given as the function of the Urbach energy. The absorption coefficient near the fundamental absorption edge is exponentially dependent on the incident photon energy [22].

$$
\alpha(E)=\alpha_{0} \exp \left(\frac{E}{E_{U}}\right)
$$

where $\alpha_{o}$ is a constant, $E$ is the photon energy and $E_{U}$ is an Urbach energy.

The Urbach energy characterizes the slope of the exponential edge region, and the inverse of the slope gives the width of the localized states associated with amorphous state in the band gap [23]. $E_{U}$ value that determines the steepness of the Urbach tail depends on the structural disorder of sample [24]. The Urbach energy $E_{U}$ is given as Eq. (3) [25].

$$
E_{U}=\frac{k T}{\sigma}
$$

where $\sigma$ is steepness parameter, $k$ is Boltzmann constant and $T$ is the absolute temperature. Urbach energy is calculated by fit-

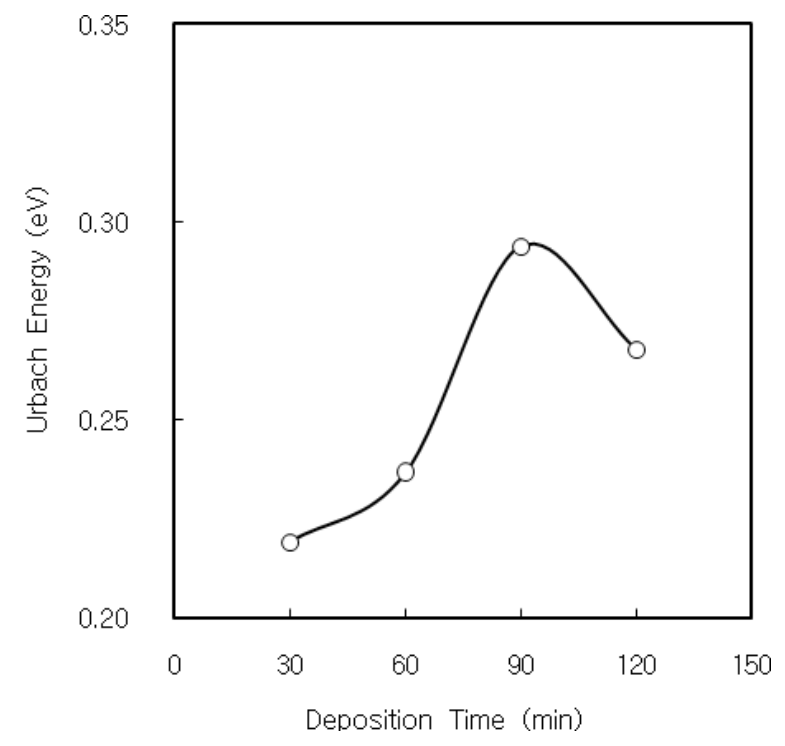

Fig. 4. Urbach energy of CdS thin films as a function of the deposition time.

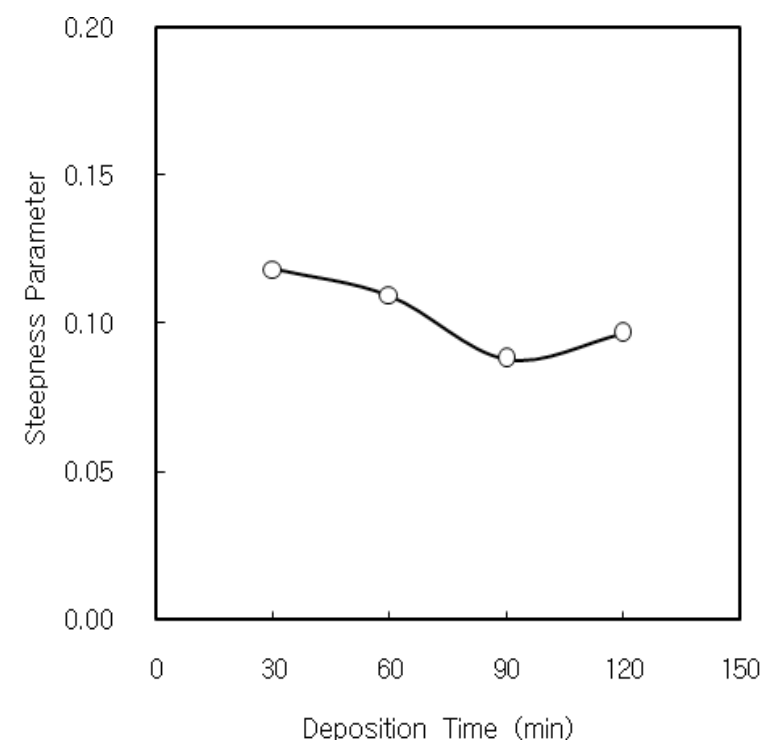

Fig. 5. Steepness parameter of CdS thin films as a function of deposition time.

ting an exponential function to the slope of the linear portion of $\ln \alpha$ vs. $h v$ plot. To obtain the Urbach energy of CdS thin films, the experimental optical absorption coefficient is fitted. Figures 4 and 5 show the Urbach energy and steepness parameter of CBD CdS thin films, respectively. The Urbach energy and steepness parameter of the 2,900 $\AA$-thick CdS thin film deposited for 60 minutes were $0.24 \mathrm{eV}$ and 0.11 , respectively. The Urbach energies of CdS thin films deposited above 90 minutes are higher than the films deposited below 60 minutes as shown in Fig. 4. It is known that the quality of CBD CdS thin film is related to the deposition time and film thickness. The Urbach energy of CdS thin film depends on the structural defects, dislocation density and some defects of the vacancy and interstitial states in the films.

The relation between the absorption coefficient and $\alpha$ energy of incident light $h v$ for a direct transition is used to obtain the band gap [21] 


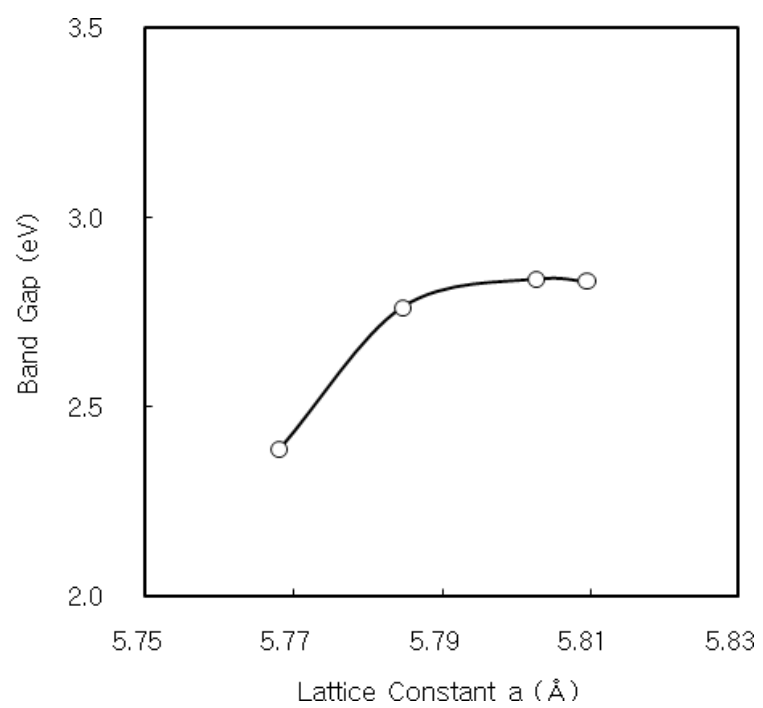

Fig. 6. Optical band gap of CdS thin films as a function of the lattice constant.

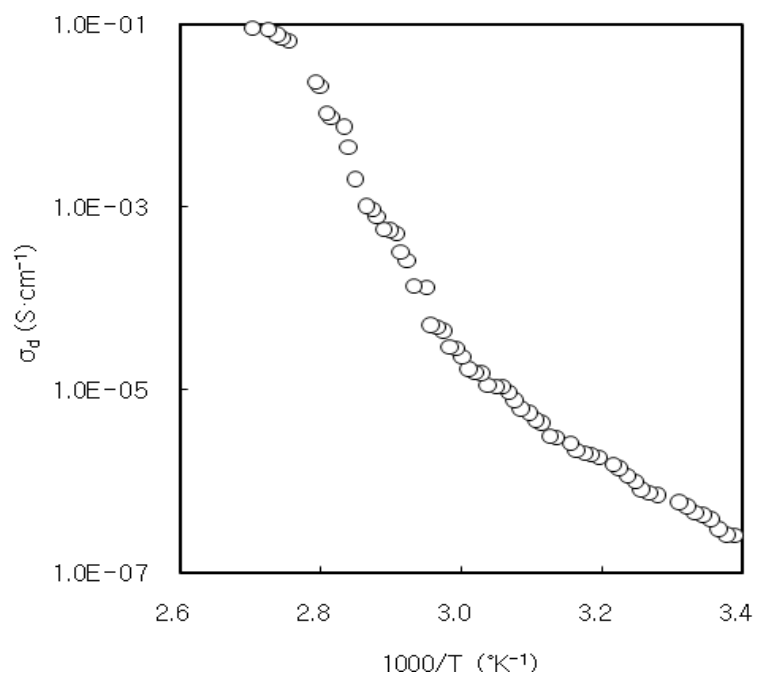

Fig. 7. Temperature dependence of the dark conductivity for 2,900 $\AA$ thick CdS thin film deposited for 60 minutes.

$$
\alpha h v=A\left(h v-E_{g}\right)^{1 / 2}
$$

where $A$ is a constant and $E_{g}$ is the energy band gap. The optical band gap of CdS thin films is determined by extrapolating the straight line portion of the plot of $(\alpha h v)^{2}$ vs. $h v$ to energy axis [21] From the $(\alpha h v)^{2}$ vs. $h v$ plot, the band gap of the 2,900 $\AA$-thick CdS film prepared for 60 minutes was $2.83 \mathrm{eV}$. On the other hand, Fig. 6 shows the optical band gap of CdS thin films as the function of the lattice constant. The optical band gap of CdS thin films increases and finally saturates with increasing the lattice constant. This is attributed to the change of internal strain within the CdS thin film.

The activation energy $E_{a}$ of the CdS thin film is determined from the temperature dependence of dark conductivity.

$$
\sigma_{d}=\sigma_{0} \exp \left(-E_{a} / k T\right)
$$

where $\sigma_{d}$ is dark conductivity at temperature $T, \sigma_{0}$ is dark conductivity at room temperature, $k$ is Boltzmann's constant and $T$

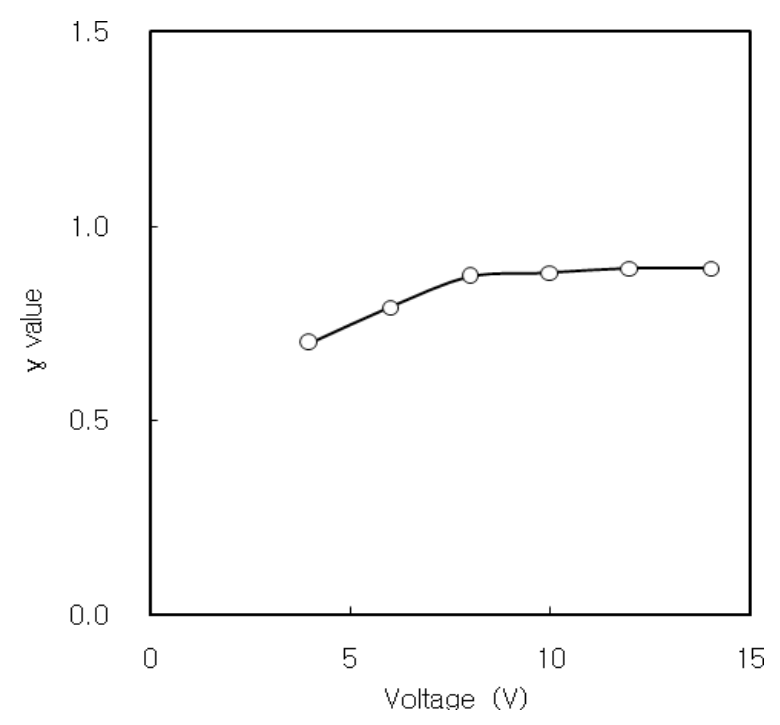

Fig. 8. $\gamma$ value for the 2,900 $\AA$-thick CdS thin film as a function of applied voltage.

is absolute temperature. Electrical conductivity was measured by using the DC two probe method. $E_{a}$ represents the location of trap levels below the conduction band of CdS thin film [26]. The temperature dependence of the dark conductivity of 2,900 $\AA$-thick CdS thin film was investigated at a bias voltage of $10 \mathrm{~V}$.

The temperature dependence of the dark conductivity of CdS thin film was composed of two regions as shown in Fig. 7. The dark resistivity of 2,900 $\AA$-thick CdS thin film at room temperature was of the order of $10^{6} \Omega \mathrm{cm}$. The high resistivity of CdS thin film is attributed to the nanocrystalline nature, dislocations and defects of the film [27]. The activation energies of the 2,900 $\AA$-thick CdS thin film at low and high temperature regions were $14 \mathrm{meV}$ and $31 \mathrm{meV}$, respectively. It is considered that these activation energies correspond to donor levels associated with the shallow traps or surface states of CdS thin film. The low activation energy of $14 \mathrm{meV}$ at low temperature region was nearly the same as the value of $E_{B}$ activation energy $13.7 \mathrm{meV}$ obtained by temperature dependence of the photoluminescence intensity [28]. The 2,900 $\AA$-thick CdS thin film has a bandgap of $2.83 \mathrm{eV}$, in which sulphur vacancies create shallow donor levels $14 \mathrm{meV}$ and $31 \mathrm{meV}$ below the conduction band.

The photocurrent $I_{p h}$ of CdS thin film was measured by applying constant voltage between In/Ag electrodes. The photocurrent obeys the power law as Eq. (6) [29].

$$
I_{p h} \propto F^{\gamma}
$$

where $F$ is the light intensity and $\gamma$ is the exponent, which determines the recombination mechanism [30]. The value of $\gamma$ for the CdS thin film was calculated from the slope of $\ln I_{p h}$ vs. $\ln F$ plot. The value of $\gamma$ for the 2,900 $\AA$-thick CdS thin film was investigated as the function of applied voltage as shown in Fig. 8. The value of $\gamma$ for the 2,900 $\AA$-thick CdS thin film was 1 at $10 \mathrm{~V}$, and it saturates with increasing the applied voltage.

\section{CONCLUSIONS}

Nanocrystalline CdS thin films were deposited on cleaned glass substrates by CBD. The structural, optical and photoconductive properties of CdS thin films were investigated. From the XRD measurement, three diffraction peaks correspond to (111), 
(220) and (311) reflections of the cubic phase at $2 \Theta$ of $26.5^{\circ}, 44^{\circ}$ and $52^{\circ}$, respectively. The dislocation density of CdS thin film initially decreases with increasing the film thickness, and it is constant over the thickness of 2,500 $\AA$. It is considered by the decrease of the internal strain with increasing the film thickness. Also, the dislocation density decreases with increasing the crystallite size. The Urbach energies of CdS thin films deposited above 90 minutes are higher than the films deposited below 60 minutes. It is known that the quality of CBD CdS thin films is related to the deposition time and film thickness. The optical band gap of CdS thin films increases and finally saturates with increasing the lattice constant. The electrical conductivity and photocurrent of CdS thin film were investigated using the DC two probe method. The activation energies of the 2,900 $\AA$-thick CdS thin film at low and high temperature regions were $14 \mathrm{meV}$ and $31 \mathrm{meV}$, respectively. It is considered that these activation energies correspond to the donor levels associated with shallow traps or surface states of CdS thin film. On the other hand, the 2,900 A-thick CdS thin film has a bandgap of $2.83 \mathrm{eV}$, in which sulphur vacancies create shallow donor levels $14 \mathrm{meV}$ and $31 \mathrm{meV}$ below the conduction band. Also, the value of $\gamma$ for the 2,900 $\AA$-thick $\mathrm{CdS}$ thin film was 1 at $10 \mathrm{~V}$, and it saturates with increasing the applied voltage.

\section{ACKNOWLEDGMENTS}

The XRD and transmittance of CdS thin films were measured at Korea Basic Science Institute (KBSI). And FE-SEM of CdS thin films was conducted at Center for Instrumental Analysis at Andong National University.

\section{REFERENCES}

[1] P. K. Ghosh, S. Jana, U. N. Maity, and K. K. Chattopadhyay, Physica E 35, 178 (2006) [DOI: 10.1016/j.physe.2006.07.029].

[2] N. Romeo, A. Bosio, R. Tedeschi, A. Romeo, and V. Canevari, Sol. Energy Mater. Sol. Cells 58, 209 (1999) [DOI: 10.1016/s09270248(98)00204-9].

[3] A. Romeo, D. L. Bätzner, H. Zogg, C. Vignali, and A. N. Tiwari, Sol. Energy Mater. Sol. Cells 67, 311 (2001) [DOI: 10.1016/ s0927-0248(00)00297-x].

[4] T. Negami, Y. Hashimoto, and S. Nishiwaki, Sol. Energy Mater. Sol. Cells 67, 331 (2001) [DOI: 10.1016/s0927-0248(00)00300-7].

[5] D. Abou-Ras, G. Kostorz, A. Romeo, D. Rudmann, and A. N. Tiwari, Thin Solid Films 480-481, 118 (2005) [DOI: 10.1016/ j.tsf.2004.11.033].

[6] V. Singh, B. P. Singh, T. P. Sharma, and R. C. Tyagi, Opt. Mater. 20, 171 (2002) [DOI: 10.1016/s0925-3467(02)00043-5].

[7] S. A. Al Kuhaimi, Vacuum 51, 349 (1998) [DOI: 10.1016/s0042207x(98)00112-2].

[8] A. Podesta, N. Armani, G. Salviati, N. Romeo, A. Bosio, and M.
Prato, Thin Solid Films 511-512, 448 (2006) [DOI: 10.1016/ j.tsf.2005.11.069].

[9] S. A. Al Kuhaimi, Sol. Energy Mater. Sol. Cells 52, 69 (1998) [DOI: 10.1016/s0927-0248(97)00272-9].

[10] S. Mathew, P. S. Mukerjee, and K. P. Vijayakumar, Thin Solid Films 254, 278 (1995) [DOI: 10.1016/0040-6090(94)06257-1].

[11] O. Vigil, I. Riech, M. Garcia-Rocha, and O. Zelaya-Angel, J. Vac. Sci. Technol. A 15, 2282 (1997) [DOI: 10.1116/1.580735].

[12] I. Yu, T. Isobe, and M. Senna, Mater. Res. Bull. 30, 975 (1995) [DOI: 10.1016/0025-5408(95)00082-8].

[13] W. J. Danaher, L. E. Lyons, and G. C. Morris, Sol. Energy Mater. 12, 137 [DOI: 10.1016/0165-1633(85)90029-2].

[14] P. J. Sebastian, J. Campos, and P. K. Nair, Thin Solid Films 227, 190 (1993) [DOI: 10.1016/0040-6090(93)90038-q].

[15] A. J. Haider, A. M. Mousa, and S. M. H. Al-Jawad, J. Semicond. Technol. Sci. 8, 326 (2008).

[16] N. R. Pavaskar, C. A. Menezes, and A. P. B. Sinha, J. Electrochem. Soc. 124, 743 (1977) [DOI: 10.1149/1.2133398].

[17] O. Zelaya-Angel, F. d. L. Castillo-Alvarado, J. Avendano-Lopez, A. Escamilla-Esquivel, G. Contreras-Puente, R. Lozada-Morales, and G. Torres-Delgado, Solid State Commun. 104, 161 (1997) [DOI: 10.1016/s0038-1098(97)00080-x],

[18] P. P. Hankare, A. D. Jadhav, V. M. Bhuse, A. S. Khomane, and K. M. Garadkar, Mater. Chem. Phys. 80, 102 (2003) [DOI: 10.1016/ s0254-0584(02)00344-9].

[19] M. Thambidurai, N. Murugan, N. Muthukumarasamy, S. Vasantha, R. Balasundaraprabhu, and S. Agilan, Chalcogenide Lett. 6, 171 (2009).

[20] M. Sridharan, S. K. Narayandass, D. Mangalaraj, and H. C. Lee, Cryst. Res. Technol. 37, 964 (2002) [DOI: 10.1002/15214079(200209)37:9<964::aid-crat964>3.0.co;2-r].

[21] S. Prabahar and M. Dhanam, J. Cryst. Growth 285, 41 (2005) [DOI: 10.1016/j.jcrysgro.2005.08.008].

[22] S. Ilican, M. Caglar, and Y. Caglar, J. Opt. Adv. Mater. 9, 1414 (2007).

[23] F. Yakuphanoglu and M. Sekerci, Opt. Appl. 35, 209 (2005).

[24] A. E. Rakhshani and A. S. Al-Azab, J. Phys.: Condens. Matter 12, 8745 (2000) [DOI: 10.1088/0953-8984/12/40/316].

[25] A. Ates, M. A. Yildirim, M. Kundakçi, and M. Yildirim, Chin. J. Phys. 45, 135 (2007).

[26] V. R. Shinde, T. P. Gujar, C. D. Lokhande, R. S. Mane, and S. H. Han, Mater. Chem. Phys. 96, 326 (2006) [DOI: 10.1016/ j.matchemphys.2005.07.045].

[27] R. K. Nkum, A. A. Adimado, and H. Totoe, Mater. Sci. Eng., B 55, 102 (1998) [DOI: 10.1016/s0921-5107(98)00193-7].

[28] W.-D. Park, Trans. Electr. Electron. Mater. 11, 170 (2010) [DOI: 10.4313/TEEM.2010.11.4.170].

[29] A. Dahshan, H. H. Amer, A. H. Moharam, and A. A. Othman, Thin Solid Films 513, 369 (2006) [DOI: 10.1016/ j.tsf.2006.01.062].

[30] M. Singh Kamboj, G. Kaur, and R. Thangaraj, Thin Solid Films 420-421, 350 (2002) [DOI: 10.1016/s0040-6090(02)00848-9]. 